\title{
Personalized Multi-Criteria Decision Strategies in Location-Based Decision Support
}

\author{
Claus Rinner
}

University of Toronto

\section{Martin Raubal}

University of Münster

digital.library.ryerson.ca/object/273

Please Cite:

Rinner, C., \& Raubal, M. (2004). Personalized multi-criteria decision strategies in location-based decision support. Geographic Information Sciences, 10(2), 149156.

doi:10.1080/1x0824000409480666

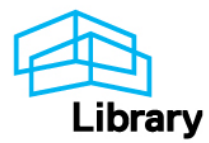




\title{
Personalized Multi-Criteria Decision Strategies in Location-Based Decision Support
}

\author{
Rinner Claus $^{1}$, Raubal Martin ${ }^{2}$ \\ ${ }^{1}$ Department of Geography, University of Toronto, 100 Saint George Street, Toronto ON M5S 3G3, Canada, \\ E-mail:rinner@geog.utoronto.ca \\ ${ }^{2}$ Institute for Geoinformatics, University of Münster, Robert-Koch-Str. 26-28, 48149 Münster, Germany, \\ E-mail:raubal@uni-muenster.de
}

\begin{abstract}
Location-based services (LBS) assist people in decision-making during the performance of tasks in space and time. Current LBS support spatial and attribute queries, such as finding the nearest Italian restaurant from the current location of the user, but they are limited in their capacity to evaluate decision alternatives and to consider individual decision-makers' user preferences. We suggest that LBS should provide personalized spatial decision support to their users. In a prototype implementation, we demonstrate how user preferences can be translated into parameters of a multi-criteria evaluation method. In particular, the Ordered Weighted Averaging (OWA) operator allows users to specify a personal decision strategy. A traveler scenario investigating the influence of different types of users and different decision strategies on the outcome of the analysis serves as a case study.

Keywords

Location-Based Services (LBS), Multi-Criteria Evaluation, Ordered Weighted Averaging (OWA), Personalization, Spatial Decision Support Systems (SDSS)
\end{abstract}

\section{INTRODUCTION}

Location-based services (LBS) assist people in decisionmaking while they perform tasks in space and time. LBS pose new challenges to software applications for mobile devices and benefit from research in geographic information science and its founding disciplines, geography and information technology.

Current research topics related to LBS include network architectures and standards (Adams, et al., 2003; Peng, Tsou, 2003; Ahn, et al., 2004), positioning techniques and recording of space-time activity (Mountain, Raper, 2001; Miller, 2003; Spinney, 2003; Worboys, Duckham, 2004), market opportunities and business cases for LBS (Beinat, 2001; Benson, 2001; Barnes, 2003), user interface customization and personalization (Hjelm, 2002; Zipf, 2002a, 2002b, 2003; Gartner, et al., 2003) and locational privacy (Armstrong, 2002; Myles, et al., 2003).

Typical applications of LBS include navigation services (Winter, et al., 2001; Chincholle, et al., 2002; Winter, 2002; Choi, Tekinay, 2003; Smith, et al., 2004), tourist information systems (Zipf , 2002a, 2002b; Berger, et al., 2003; Hinze , Voisard, 2003), and emergency response and disaster management (Erharuyi, Fairbairn, 2003).

Location-based navigation services provide decision support by answering spatial queries, e.g. "find the shortest route from current location to target location", and combined spatial and attribute queries, e.g. "find the nearest Italian restaurant from current location". But decision support methods in geographic information systems (GIS) go beyond simple querying in that they enable users to evaluate and rank decision alternatives based on multiple criteria. GIS-based multi-criteria evaluation is commonly used in applications such as site suitability analysis (Malczewski, 1999, Heywood, et al., 2002). This set of methods, which allows decision-makers a trade-off between good and poor properties of decision alternatives has not yet been introduced to LBS (Rinner, 2003a).

LBS have also been found insufficient in considering individual user preferences, time constraints, and possible subtasks (Raubal, et al., forthcoming 2004). This paper introduces an approach for representing user preferences in a qualitative way and using them as input for multi-criteria evaluation. Users specify decisionrelevant attributes to be used as evaluation criteria; identify good, fair, and poor criterion values or value ranges to allow for comparison of standardized criterion values; and define the relative importance of criteria by assigning weights. The weighted criterion values are then combined based on a decision rule, resulting in an evaluation score for each decision alternative. We use the Ordered Weighted Averaging (OWA) decision rule (Yager, 1988) that allows users to specify a personal decision strategy as part of their decision-related preferences.

Section II introduces a background scenario for the description of location-based decision services: the case of travelers with different user types and decision strategies. The following section summarizes the principles of decision analysis in GIS and describes the steps of performing a multi-criteria evaluation in an LBS context. Section IV provides an overview of the OWA method and defines "decision strategies" within the OWA framework. Section V describes the architecture of the prototype implementation and its functionality. In section VI

$1082-4006 / 05 / 1101-61 \$ 5.00$

(C)2005 The International Association of Chinese Professionals in Geographic Information Science (CPGIS) 
the results of the case study are explained. The final section draws conclusions and outlines directions for future work.

\section{BACKGROUND SCENARIO}

A traveler is in a foreign city and decides to extend his/her stay. It is late in the evening and he/she needs to find a hotel. With current LBS it is possible to locate all hotels close to the traveler's position, e.g. those within 500 meters. But the traveler wants the hotel to best fit his/her preferences, such as a reasonable price for the room, a private bath, and a late checkout time. All of these criteria are subjective and therefore assigned different importance by different travelers. The following framework demonstrates how this task can be solved by a location-based service that integrates qualitative user preferences and multi-criteria decision analysis.

A personalized LBS must allow for focalization, i.e. the adaptation to different decision situations (Winter, et al., forthcoming 2004). In general, these decision situations can vary in different aspects, such as mode of travelling, user type, environment, and individual spatial and cognitive strategies of the user. In this work we focus on two aspects: The first part of the case study explores the need for personalized information of three different user groups (business traveler, tourist, low-budget tourist). The second part of the case study investigates different decision strategies on a scale ranging from optimistic to pessimistic, for one particular user group (business traveler).

For the case study described in section VI, a data set for the city of Münster, Germany, is used. The base map consists of the street network. Hotels were digitized as points according to their location on an analog city map. The hotel feature class has the attributes Name, Address, Price, Private bath, and Check-out time associated with each feature. All values for these attributes except the last one were taken from the City of Münster Hotel Guide (Stadt Münster, 2003). Price is the average price for a single room and Private bath is a Boolean value. Check-out times were gathered by calling hotel receptions. Data pre-processing was performed in ESRI's ArcMap.

\section{MULTI-CRITERIAEVALUATION}

Multi-criteria evaluation is a decision support methodology, which is based on the idea that humans use multiple decision criteria to determine the best solution. Multi-criteria decision rules have been implemented in GIS since the 1990s including the Simple Additive Weighting, Analytic Hierarchy Process, Ideal Point Analysis, Concordance, and OWA methods (Janssen, Rietveld, 1990; Carver, 1991; Church, et al., 1992; Banai, 1993; Pereira, Duckstein, 1993; Jankowski, 1995; Eastman, 1997; Malczewski, 1999; Thill, 1999; Jankowski, et al., 2001). Some GIS-based spatial decision support systems allow testing different standardization and aggregation procedures to explore differences in the results (Heywood, et al., 1995; Rinner, Malczewski, 2002). Multi-criteria evaluation has been implemented in conjunction with online GIS (Rinner, 2003a, 2003b) but to the authors' knowledge, it has not yet been suggested to integrate multi-criteria evaluation with LBS.

The first part of the task described in the background scenario above, i.e. determining a set of nearby hotels, is solved by selecting hotels within a certain radius of the user's current location. This selection uses a decision rule that is noncompensatory. Non-compensatory operators do not allow for a trade off between good and poor criteria values (Jankowski, 1995). In other words, the distance from the current position is a "hard" selection criterion. This type of criterion is typically applied in present LBS. Solving the second part of the task requires the integration of compensatory decision rules, which allow users to control the trade-off between good and poor characteristics of alternative locations. Compensatory rules require standardization to make criterion values comparable. These values are then aggregated to a single evaluation score per alternative according to the rule. The user typically selects the highest scoring alternative.

In this paper we will aggregate multiple criteria into a single evaluation score for each decision alternative according to the OWA rule. We suggest an interactive approach, which lets the user (1) select decision criteria; (2) express his/her preferred criteria values on a qualitative scale; (3) define the importance of each criterion; (4) define a personal decision strategy through the settings of the OWA method. Steps (1) to (3) are described in the following paragraphs while step (4) is discussed in more detail in section 4 .

\section{A. Selection of decision criteria}

In a vector-based GIS context, attributes of geographic features may serve as decision criteria while in a raster-based system, different raster datasets (maps) would represent the decision criteria (Heywood, et al., 2002). In a location problem such as the hotel selection, the decision alternatives would typically be modeled as features. Thus we will allow users to select the attributes of hotel features on which to base their decision, and our approach performs calculations in the feature attribute table.

A second concern regarding decision criteria relates to the levels of measurement (Chrisman, 1997) that can be handled in the decision analysis. We will allow users to work with numerical, ordinal, as well as nominal criteria. However, multicriteria evaluation requires commensurate, numerical criteria so that all selected criteria have to be transformed to a common, numerical scale as described in the following paragraph.

\section{B. Standardization of criteria}

Standardization of criteria is required to allow for trade-off between criteria in the calculation of the final evaluation score. 
In order to improve the system's usability we work with a qualitative "Good - Fair - Poor" scale. According to the rankorder rule, the qualitative values can be transformed to numerical values of 3,2 , and 1 , respectively, for further processing. Table 1 shows an example of standardized criterion values for a business traveler.

Table 1. Example of standardized criterion values for a business traveler. Standardization occurs on a qualitative scale to facilitate the user's preference statements

\begin{tabular}{ccc}
\hline Criterion & Original values & Standardized values \\
\hline \multirow{2}{*}{ Room price } & $80-120 \bullet$ & Good \\
$50-80 \bullet$ & Fair \\
& $>120 \bullet$ & Poor \\
Private bath & Yes & Good \\
& No & Poor \\
& $>11: 00$ & Good \\
Check-out time & $11: 00$ & Fair \\
& $<11: 00$ & Poor \\
\hline
\end{tabular}

This approach can be described as a value/utility function (Russell, Norvig, 1995) in which the user transforms ranges of attribute values to a single utility score according to his/her preferences. In our approach, the value/utility function allows for a transformation of attribute intervals (e.g. price ranges) or attribute categories (e.g. no private bath) into utility scores. Another common method of deriving commensurate decision criteria is linear scale transformation, which is limited to numerical attribute data.

\section{Importance weights for criteria}

The OWA decision rule allows the user to specify a set of weights representing the relative importance of criteria according to the user's preferences. The weight of a criterion defines its impact in the compensatory aggregation. For example, if price is considered twice as important as having a private bath, then the drawback of a high price cannot be fully compensated by the benefit of a private bath. By default, criterion weights are set to $1 / n$ to represent $n$ equally important criteria.

\section{DECISION STRATEGIES}

The OWA method is a parameterized family of multi-criteria aggregation operators proposed by Yager (1988). OWA has been described in the context of GIS-based multi-criteria analysis by Malczewski (1999) and Jiang \& Eastman (2000). IDRISI (Eastman ,1997) and CommonGIS (Rinner, Malczewski, 2002) contain an OWA method for raster data, and vector data, respectively.

OWA is characterized by a set of order weights in addition to the importance weights mentioned before. With OWA, the standardized criterion values $a_{i j}$ are multiplied with the corresponding importance weights $w_{j}$ (if importance weights are used at all). Rather than being aggregated (as with the Simple Additive Weighting method), these terms are re-ordered by descending value. Thus, $b_{i k}=w_{j} a_{i j}$ denote the weighted criterion values for alternative $i$, but they are re-ordered so that $b_{i 1}>\ldots>b_{i n}$. Final evaluation scores are calculated as the sum of the re-ordered standardized criterion values with an additional weighting of the positions. The score of alternative $i$ is $s_{i}=\Sigma v_{k} b_{i k}$, where $v_{k}$ is the order weight for the $k$-th position in the re-ordered sequence of weighted criterion values (Malczewski, 1999). The order weights thus are used to emphasize the better or the poorer properties of each decision alternative (independent of the actual criteria that constitute those properties).

The set of order weights is a parameter that determines an instance of the OWA operator. On the one hand, order weights $(1,0, \ldots, 0)$ will give full weight to the best criterion outcome of each alternative, independent of how poorly an alternative may perform in some other criteria. Alternatives with a single outstanding property will be ranked highest. This is called a risk-taking or optimistic decision strategy. On the other hand, order weights $(0, \ldots, 0,1)$ will give full weight to the poorest criterion outcome, independent of how well an alternative performs otherwise. Alternatives with the "least poor" properties will rank highest under this risk-averse or pessimistic decision strategy. Between these two extremes there is a continuum of intermediate strategies, the most important of which is the neutral strategy that does not emphasize any position in the re-ordered criterion values. The neutral strategy is achieved by using order weights of $v_{k}=1 / n$ for $k=1, \ldots, n$, and it yields scores that are proportional to those resulting from simple additive weighting. The ranks derived from scores under these two aggregation methods are therefore the same. Eastman (2000) describes decision strategies with reference to GIS applications, focussing on the decisionmakers' risk propensity and the desired level of trade-off between criteria.

Order weights could be defined manually by the user of an application, but Yager (1988) suggests a way of calculating the order weights based on a parameter $\alpha$, which corresponds to the decision strategy. $v_{k}=(k / n)^{\alpha}-((k-1) / n)^{\alpha}$ defines a set of valid order weights for a given number $n$ of criteria. The $\alpha$ parameter allows a mapping of labels on a qualitative scale to order weights. As shown in Table 2, we chose five labels ranging from "optimistic" through "neutral" to "pessimistic" to facilitate the user's definition of a decision strategy. The mapping of these labels to values of the parameter (and thus, to sets of order weights) is non-deterministic. We chose $\alpha$ values that would yield approximately symmetrical order weights for the five sample decision strategies. A different way of specifying the order weights uses linguistic quantifiers such as "all", "most", "half", etc. to denote the proportion of re-ordered positions which are included in the aggregation (Yager, 1996). 
Table 2. Correspondence between decision strategy, order eights, and OWA parameter for two and three criteria. Order weights emphasize certain positions in the re-ordered criterion values as indicated by bold font

\begin{tabular}{lccc}
\hline $\begin{array}{l}\text { Decision } \\
\text { strategy }\end{array}$ & Order weights $(n=2)$ & Order weights $(n=3)$ & Parameter $(\hat{A})$ \\
\hline Optimistic & $\mathbf{1 . 0 0}, 0.00$ & $\mathbf{1 . 0 0}, 0.00,0.00$ & 0.001 \\
$\begin{array}{l}\text { Moderately } \\
\text { optimistic }\end{array}$ & $\mathbf{0 . 8 1}, 0.19$ & $\mathbf{0 . 7 2}, 0.17,0.11$ & 0.3 \\
Neutral & $0.50,0.50$ & $0.33,0.33,0.33$ & 1.0 \\
$\begin{array}{l}\text { Moderately } \\
\text { pessimistic }\end{array}$ & $0.13, \mathbf{0 . 8 8}$ & $0.04,0.26, \mathbf{0 . 7 0}$ & 3.0 \\
Pessimistic & $0.00, \mathbf{1 . 0 0}$ & $0.00,0.02, \mathbf{0 . 9 8}$ & 10.0 \\
\hline
\end{tabular}

\section{IMPLEMENTATION}

\section{A. Architecture}

A prototype of the personalized LBS was implemented using ESRI's ArcPad (ESRI, 2004) and the data set described above for the city of Münster, Germany. ArcPad is a mobile GIS software that runs on handheld computers. For demonstration, we use a Windows XP desktop emulation of ArcPad.

This prototype was implemented as an ArcPad "applet" using the ArcPad Studio development environment. The applet file contains XML tags that define a custom toolbar which is added to ArcPad's user interface. The two tools in the toolbar are linked to procedures in a VBScript document. The applet also defines a multi-tab form that walks the user through the decision process. Most VBScript subroutines are activated by events in this form, e.g. the click of a button or the selection of items in a list.

The ArcPad approach to customization requires the applet and script files to be copied into the ArcPad installation folder on the handheld computer on which the tools are to be used. Our prototype is fully client-based and does not contain a server component, nor does it connect to any server while running.

\section{B. User interface and functionality}

The tool represented by a pin icon allows the user to specify his/her current position on the city street map. In the future, the position should be gathered from a connected GPS receiver although the option of relocating the position marker may still be offered for testing purposes. As soon as a position is determined, all hotels within a distance buffer (currently fixed at $500 \mathrm{~m}$ ) around this position are selected and highlighted (Figure 1(a)). The buffer distance should be made modifiable by the user through an additional user interface widget.

Clicking on the hotel choice tool opens the custom form for

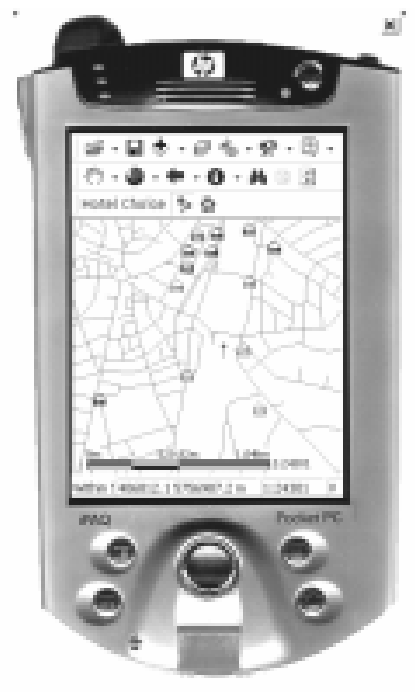

(a)

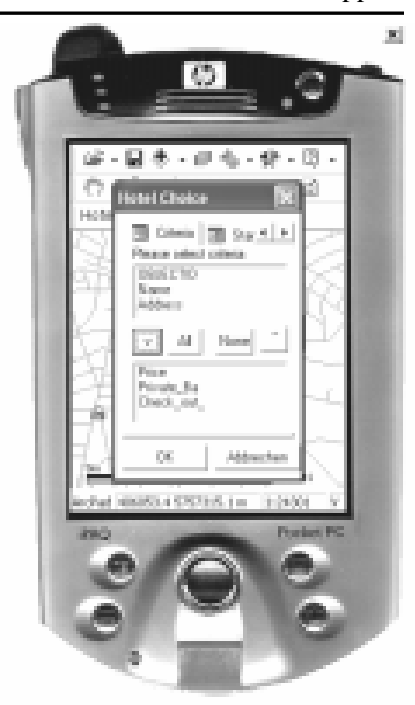

(b)
Figure 1. ArcPad desktop emulation showing the filtering and marking of nearby hotels (a) and the selection of criteria by the user (b)

the remaining user input. The form consists of four tabs ("pages" in ArcPad terminology) corresponding to the four steps identified above. The "Criteria" tab presents a list of all attributes of the hotel features. Selecting attributes to be used as criteria will move them to the bottom list (see Figure 1(b)). This selection controls further settings in the following tabs.

The "Standardization" tab suggests a way of defining attribute ranges for poor, fair, and good levels for each criterion. The setting requires the user to select the criterion, then iteratively select the three standardization levels, and define the range in terms of minimum and maximum value for each level (see Figure 2(a)). The range definition is facilitated by offering the list of

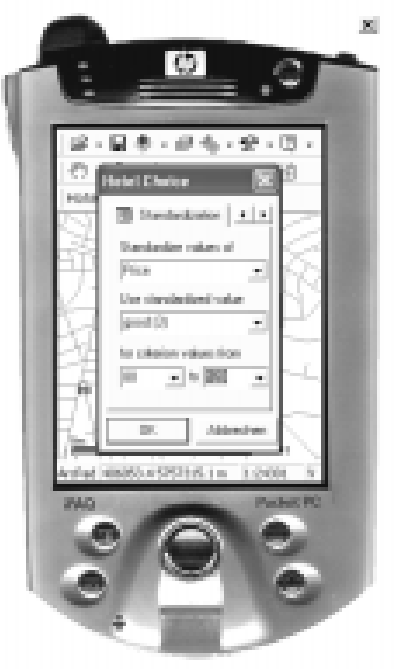

(a)

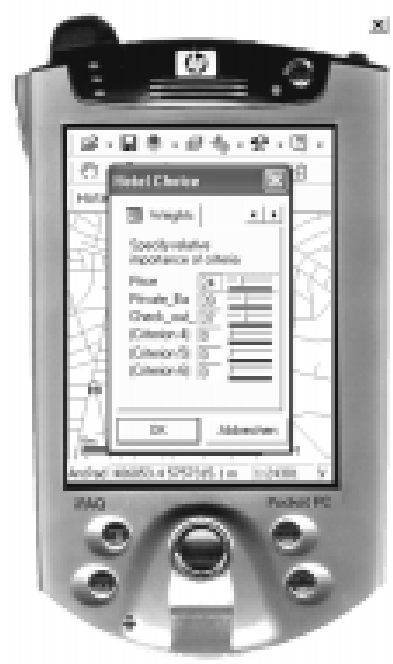

(b)
Figure 2. ArcPad desktop emulation showing the standardization of criteria (a) and the definition of relative importance weights by the user (business traveller profile) (b) 
all attribute values for the selected hotels.

The "Weights" tab allows the user to specify the relative importance of criteria on a percent range, with weights adding up to a total of $100 \%$ (see Figure 2(b)). Changing the weight for one criterion using the corresponding slider will proportionally adapt the weights for the other criteria to preserve the correct total. Currently, the applet is limited to a maximum of six criteria due to the space limitations for positioning the slider widgets.

The "Strategy" tab provides a choice among a limited number of pre-defined decision strategies, ranging from "optimistic" to "pessimistic" (see Figure 3(a)). The strategy affects the evaluation result in terms of the influence exerted by the better or worse criterion outcomes of each alternative. The link between the user's personal decision strategy and the mathematical formulation of the OWA method was described in section IV.

Clicking the "OK" button for the custom form triggers a subroutine, which reads all user input from the form and performs the OWA evaluation method. The resulting final scores are stored as a new field in the hotel feature attribute table. This field is used for labelling the hotel markers on the map so that the user can find the best-ranked hotel. In the final map only those hotels within the buffer zone, whose scores fall within the top three overall scores are labelled (see Figure 3(b)).

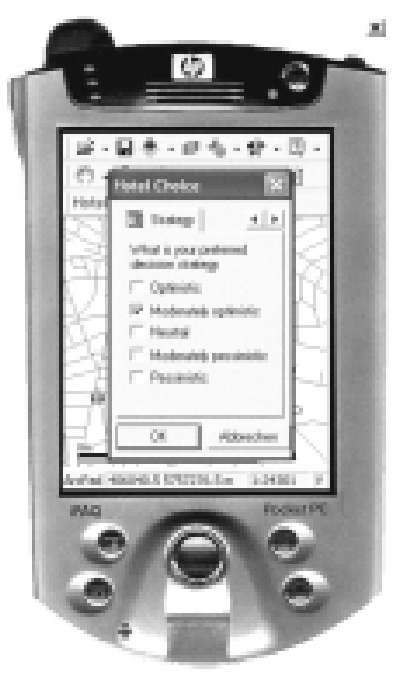

(a)

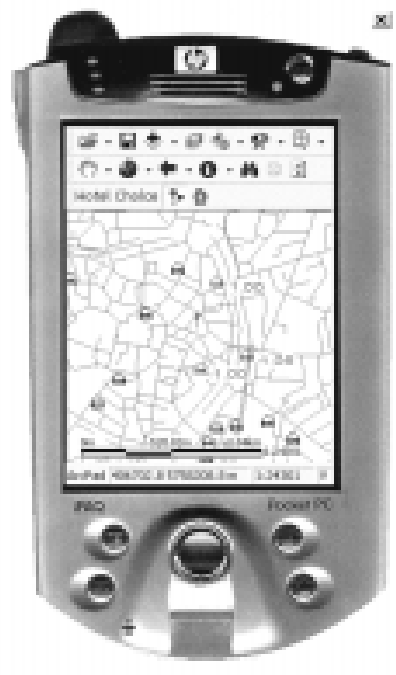

(b)
Figure 3. ArcPad desktop emulation showing the selection of a decision strategy (a), and the result of the OWA evaluation method (business traveller profile, moderately optimistic decision strategy) (b)

\section{RESULTS OF THE CASE STUDY}

This section presents the results of the case study, which investigates the influence of various user profiles and decision strategies on the outcome of the analysis. User types are defined by different standardization choices and different importance attached to criteria by weighting, whereas decision strategies are determined by the settings of the OWA aggregation rule as described in section IV. The following description of user types focuses on the different criterion weights for the three user types, a summary of which are given in Table 3. The complete test profiles including the standardization choices as well as the evaluation results can be found at http://ifgi.uni-muenster.de/ raubal/ Publications/ RefJournals/Rinner\&Raubal_OWA-Results.pdf.

Table 3. Sample user preferences with respect to relative importance between criteria

\begin{tabular}{cccc}
\hline User type / Criterion weights & Room price & Private bath & Check-out time \\
\hline Business traveler & $24 \%$ & $39 \%$ & $37 \%$ \\
Tourist & $33 \%$ & $33 \%$ & $33 \%$ \\
Low-budget tourist & $58 \%$ & $21 \%$ & $21 \%$ \\
\hline
\end{tabular}

\section{A. Varying the user type}

In the first part of the case study, the traveler scenario is tested by analyzing various user types - a business traveler, a tourist, and a low-budget tourist-with different preferences. In the description of the prototype implementation above, Figures 1, 2, and 3 use the business traveler profile.

In the evaluation results (see Table 4), one hotel from the initial selection has the maximum score of 3.00 for the business traveler profile. The scores of the other hotels in the buffer zone amount to 2.74 and 1.74 respectively. Those alternatives are therefore less preferable according to this user's preferences. This is due to lower scores for the attributes Price and Private bath. Note that for the business traveler, the attributes Private bath and Check-out time received higher weights because the hotel price is paid by his/her company (if within a predefined range) and therefore not so important for the traveler.

The tests for the tourist and low-budget tourist types yield plausible results too. The tourist's weights were set equally and the service suggests three reasonably priced hotels (with scores of 2.31 each). The hotel proposed to the business traveler is not considered here because it is too expensive with regard to the tourist's preferences. For the low-budget tourist a high weight (58\%) was set for the Price criterion with

Table 4. Results of the multi-criteria evaluation (weighted linear combination method) for three user profiles

\begin{tabular}{cccccc}
\hline User type / Hotel & Tryp & Ibis & City & Bockhorn & Hansa Haus \\
\hline Business traveller & $\mathbf{3 . 0 0}$ & 2.74 & 2.74 & 1.74 & 2.74 \\
Tourist & 1.98 & $\mathbf{2 . 3 1}$ & $\mathbf{2 . 3 1}$ & 1.98 & 2.31 \\
Low-budget tourist & 1.84 & 1.84 & 1.84 & $\mathbf{2 . 7 9}$ & 1.84 \\
\hline
\end{tabular}


a low-valued preferred price range. As a result, the service suggests a hotel without a private bath but at a low price. This hotel was previously disregarded for both the business traveler and the tourist.

\section{B. Varying the decision strategy}

The second part of the case study investigates the influence of different decision strategies on the outcome of the analysis. The test profile of the business traveler is analyzed with five decision strategies-optimistic, moderately optimistic, neutral, moderately pessimistic, and pessimistic —as defined in Table 2. The results for five hotels (with regard to the user's location in Figure 3(b)) are given in Table 5. Please note that the evaluation scores are generally smaller by a factor of approximately one third due to the additional order weights used for the OWA method, in comparison to the weighted linear combination method used above.

Table 5. Results of the OWA evaluation method for a business traveler choosing different decision strategies

\begin{tabular}{cccccc}
\hline $\begin{array}{c}\text { Decision } \\
\text { strategy / } \\
\text { Hotel }\end{array}$ & Martinihof & Mauritzhof & Feldmann & International & $\begin{array}{c}\text { Busche am } \\
\text { Dom }\end{array}$ \\
\hline Optimistic & $\mathbf{1 . 1 7}$ & $\mathbf{1 . 1 7}$ & $\mathbf{1 . 1 7}$ & $\mathbf{1 . 1 7}$ & $\mathbf{1 . 1 7}$ \\
$\begin{array}{c}\text { Moderately } \\
\text { optimistic }\end{array}$ & 1.00 & $\mathbf{1 . 0 5}$ & 1.00 & 0.96 & 0.96 \\
$\begin{array}{c}\text { Neutral } \\
\text { Moderately } \\
\text { pessimistic }\end{array}$ & 0.49 & $\mathbf{0 . 5 0}$ & 0.49 & 0.43 & 0.43 \\
Pessimistic & $\mathbf{0 . 3 8}$ & 0.26 & $\mathbf{0 . 3 8}$ & 0.37 & 0.37 \\
\hline
\end{tabular}

With an optimistic decision strategy all five hotels receive the same score because each of them has at least one outstanding property. Three of the hotels have two outstanding properties but this does not influence the result of the optimistic strategy. When using a moderately optimistic strategy, the hotel Mauritzhof receives the highest score because its two outstanding attributes Private bath and Check-out time have the two highest criterion weights (39\% and 37\% whereas Price is only weighted 24\%). This is the distinction to the optimistic strategy where only the best criterion outcome of each alternative is given the full weight. The neutral decision strategy assigns the same order weight to each attribute and leads again to the hotel Mauritzhof as the best choice. The use of a moderately pessimistic strategy also sees the hotel Mauritzhof as the winner, but only by a very small margin. This is due to the higher criterion weight for Check-out time (compared to Price). When using a pessimistic strategy the results change completely: The hotels Martinihof and Feldmann are given as best alternatives whereas now Mauritzhof is the worst choice. Using this strategy means taking the least risk by giving full weight to the poorest criterion outcome. Here, essentially the user wants to be on the safe side when choosing a hotel.
The overall values of the evaluation scores decrease along with the progression through the decision strategies due to the nature of the OWA method. Scores cannot be compared between any two strategies, but can only be used to establish a ranking within one strategy.

\section{CONCLUSIONS AND OUTLOOK}

This paper makes a case for location-based services, which are capable of supporting personal spatial decision-making by taking into account individual users' preferences. The suggested approach lets the user standardize selected criteria using qualitative utility values, and weight their relative importance. In addition, users are enabled to choose a decision strategy on a scale between optimistic and pessimistic. In our prototype implementation we used multi-criteria evaluation to support location-based decision-making. Parameters of the multi-criteria evaluation method can be directly derived from the user preferences. The test case of a hotel finder service demonstrates that different users can be offered specific choices through personalization of LBS.

The demonstrated approach is unique with respect to previous work on LBS in that it introduces multi-criteria decision making to LBS, and combines it with personalization. We take personalization one step further by using individual user preferences as input for a multi-criteria evaluation. The main advantage of such method is that in addition to the users being able to define the relative importance of criteria, they get different results to their LBS queries depending on their decision strategies, including the level of risk-taking. In this sense future LBS have the potential to represent personalization on a level that comes even closer to people's preferences.

In future versions of this tool, standardizations that have been used (e.g. good, fair, and poor hotel price ranges) and the last used criterion weights and decision strategy for each type of facility choice (hotel, restaurant) should be stored for re-use in subsequent sessions. An actual ranking of hotels could be derived from evaluation scores, and an appropriate cartographic visualization be chosen for the ranks, e.g. proportional symbol mapping (Slocum, 1999).

Future research needs to investigate the usability and usefulness of location-based decision services by conducting human subject tests addressing both the user interface design and the suggested decision support method. Such tests might also shed light on the issue of how many different levels of personalization should be distinguished. One possibility is to distinguish between a generic, a user group, and an individual level. Such distinction has consequences for the modeling and representation of user preferences. Standardizing criterion values on a qualitative scale might be problematic because it is not fully compatible with a numerical evaluation method. This problem could be addressed by either using numerical 
standardization (limited to numerical attributes), or using a qualitative aggregation rule.

Another issue concerns the architecture of the proposed service. Our implementation is entirely client-based although LBS typically require server access to keep underlying data (e.g. attributes of decision alternatives) up-to-date. We hypothesize however that the decision analysis functionality can be performed on the client as long as the processing is kept as simple as the evaluation method used in this prototype.

\section{ACKNOWLEDGEMENTS}

This paper is an extended version of a contribution to the Geoinformatics 2004 conference (Raubal, Rinner, 2004). We would like to thank Kai Altgott and Daniel Platte for providing data and assistance with ArcPad. Constructive comments by three anonymous reviewers are gratefully acknowledged. This research has been partially supported by the Natural Sciences and Engineering Research Council of Canada (NSERC) with a grant to the first author.

\section{REFERENCES}

[1] Adams P M, Ashwell G W B, Baxter R. 2003. Location-Based Services - An Overview of the Standards. BT Technology Journal, 21(1): 34-43.

[2] Ahn Y S, Park SY, Yoo S B, Bae H Y. 2004. Extension of Geography Markup Language (GML) for mobile and locationbased applications. Computational Science and its ApplicationsICCSA 2004, Lecture Notes in Computer Science, 3044: 10791088.

[3] Armstrong M P. 2002. Geographic information technologies and their potentially erosive effects on personal privacy. Studies in the Social Sciences, 27(1):19-28.

[4] Banai R. 1993. Fuzziness in geographic information systems: Contributions from the analytic hierarchy process. International Journal of Geographical Information Systems, 7(4): 315-329.

[5] Barnes S J. 2003. Developments in the M-commerce value chain: Adding value with location-based services. Geography, 88(4): 277-288.

[6] Beinat E. 2001. Location-based Services - Market and Business Drivers. GeoInformatics, 4(3): 6-9.

[7] Benson J. 2001. LBS technology delivers information where and when its needed. Business Geographics, 9(2): 20-22.

[8] Berger S, Lehmann H, Lehner F. 2003. Location-Based Services in the Tourist Industry. Information Technology \& Tourism, 5(4): 243-256.

[9] Carver S J. 1991. Integrating multi-criteria evaluation with geographical information systems. International Journal of Geographical Information Systems, 5(3): 321-339.

[10] Chincholle D, Goldstein M, Nyberg M, Eriksson M. 2002. Lost or found? A usability evaluation of a mobile navigation and location-based service. Human Computer Interaction with Mobile Devices, Lecture Notes in Computer Science, 2411: 211-224.

[11] Choi W J, Tekinay S. 2003. Location-Based Service Provisioning for Next Generation Wireless Networks. International Journal of Wireless Information Networks, 10(3): 127-139.

[12] Chrisman N. 1997. Exploring Geographic Information Systems. John Wiley, New York.

[13] Church R L, Loban S R, Lombard K. 1992. An interface for exploring spatial alternatives for a corridor location problem. Computers and Geosciences, 8(10): 1095-1105.

[14] Eastman J R. 1997. IDRISI for Windows, Version 2.0: Tutorial exercises. Graduate School of Geography, Clark University, Worcester, MA.

[15] Eastman J R. 2000. Decision Strategies in GIS. Column in Directions magazine, dated December 13, 2000. Available online at http://www.directionsmag.com/columns.php?column_id=38 [accessed 18 March 2004].

[16] Environmental Systems Research Institute, Inc. (ESRI). 2004. Mobile GIS software for field mapping applications. ArcPad product Web page. Available online at http://www.esri.com/ software/arcgis/arcpad/ index.html [accessed 31 May 2004].

[17] Erharuyi N, Fairbairn D. 2003. Mobile geographic information handing technologies to support disaster management. Geography, 88(4): 312-319.

[18] Gartner G, Uhlirz S, Pammer A, Radoczky V. 2003. Kartographische Beiträge zur Entwicklung von LBS. Kartographische Nachrichten, 1/2003: 16-22.

[19] Heywood I, Oliver J, Tomlinson S. 1995. Building an exploratory multi-criteria modelling environment for spatial decision support. Fisher P(Ed.). Innovations in GIS 2. Taylor and Francis, London, pp. 127-136.

[20] Heywood I, Cornelius S, Carver S. 2002. An introduction to Geographical Information Systems. Pearson Education, Harlow (UK).

[21] Hinze A, Voisard A. 2003. Location- and time-based information delivery in tourism. Advances in Spatial and Temporal Databases, Lecture Notes in Computer Science, 2750:489-507.

[22] Hjelm J. 2002. Creating Location Services for the Wireless Web, John Wiley, New York.

[23] Jankowski P. 1995. Integrating Geographical Information Systems and Multiple Criteria Decision-Making Methods. International Journal of Geographical Information Systems, 9(3): 251-273.

[24] Jankowski P, Andrienko N, Andrienko G. 2001. Map-centered exploratory approach to multiple criteria spatial decision making. International Journal of Geographical Information Science, 15(2): 101-127.

[25] Janssen R, Rietveld P. 1990. Multicriteria analysis and geographical information systems: An application to agricultural land use in the Netherlands. Scholten H J, Stillwell J C H (Eds.). Geographical Information Systems for Urban and Regional Planning. Kluwer Academic Publishers, Dordrecht, pp. 129_ 139.

[26] Jiang H, Eastman R R. 2000. Application of fuzzy measures in multi-criteria evaluation in GIS. International Journal of Geographical Information Systems, 14(2):173-184.

[27] Malczewski J. 1999. GIS and Multicriteria Decision Analysis. John Wiley, New York.

[28] Miller H J. 2003. What about people in geographic information science? Computers, Environment and Urban Systems, 27(5): 447-453.

[29] Mountain D, Raper J. 2001. Positioning techniques for locationbased services (LBS): characteristics and limitations of proposed solutions. Aslib Proceedings: new information perspectives, 53 (10): 404-412.

[30] Myles G, Friday A, Davies N. 2003. Preserving Privacy in Environments with Location-Based Applications. IEEE 
Pervasive Computing, 2(1): 56-64.

[31] Peng Z R, Tsou M H. 2003. Internet GIS: Distributed Geographic Information Services for the Internet and Wireless Networks. John Wiley, Hoboken, NJ.

[32] Pereira J M C, Duckstein L. 1993. A multiple criteria decisionmaking approach to GIS-based land suitability evaluation. International Journal of Geographical Information Systems, 7(5): 407-424.

[33] Raubal M, Rinner C. 2004. Multi-Criteria Decision Analysis for Location Based Services. Brandt S A(Ed.). Proceedings of the International Conference on Geoinformatics, 7-9 June 2004, Gävle, Sweden.

[34] Raubal M, Miller H, Bridwell S. 2004. forthcoming. User Centered Time Geography For Location-Based Services. Geografiska Annaler B.

[35] Rinner C. 2003a. Web-based Spatial Decision Support: Status and Research Directions. Journal of Geographic Information and Decision Analysis, 7(1): 14-31.

[36] Rinner C. 2003b. Teaching Spatial Decision Analysis with Idrisi Online. Proceedings of 6th AGILE Conference on Geographic Information Science, pp. 24-26 April, Lyon, France.

[37] Rinner C, Malczewski J. 2002. Web-enabled spatial decision analysis using Ordered Weighted Averaging (OWA). Journal of Geographical Systems, 4(4): 385-403.

[38] Russell S, Norvig P. 1995. Artificial Intelligence - A Modern Approach. Prentice-Hall, London.

[39] Slocum T. 1999. Thematic Cartography and Visualization. Prentice-Hall, Upper Saddle River, NJ.

[40] Smith J, Mackaness W, Kealy A, Williamson I. 2004. Spatial Data Infrastructure Requirements for Mobile Location Based Journey Planning. Transactions in GIS, 8(1): 23-44.

[41] Spinney J E. 2003. Mobile positioning and LBS applications.
Geography, 88(4): 256-265.

[42] Stadt Münster. 2003. Hotels in Münster, Hotelverzeichnis 2004, Stadt Münster, Münster Marketing.

[43] Thill J C. 1999. Multicriteria Decision-making and Analysis: A Geographic Information Sciences Approach. Ashgate, New York.

[44] Winter S. 2002. Modeling Costs of Turns in Route Planning. GeoInformatica, 6(4): 345-361.

[45] Winter S, Pontikakis E, Raubal M. 2001. LBS for Real-Time Navigation - A Scenario. GeoInformatics, 4(4): 6-9.

[46] Winter S, Raubal M, Nothegger C. 2004. Focalizing Measures of Salience for Route Directions. Zipf A, Meng L, Reichenbacher T(Eds.). Map-based mobile services - Theories, Methods and Implementations. Springer, Berlin.

[47] Worboys M, Duckham M. 2004. GIS - A Computing Perspective. CRC Press, Boca Raton, FL.

[48] Yager R R. 1988. On ordered weighted averaging aggregation operators in multi-criteria decision making. IEEE Transactions on Systems, Man and Cybernetics, 18(1): 183-190.

[49] Yager R R. 1996. Quantifier guided aggregation using OWA operators. International Journal of Intelligent Systems, 11:4973.

[50] Zipf A. 2002a. Adaptive context-aware mobility support for tourists. In Trends \& Controversies: Intelligent Systems for Tourism. IEEE Intelligent Systems, 17(6): 57-59.

[51] Zipf A. 2002b. User-Adaptive Maps for Location-Based Services (LBS) for Tourism.Wöber K,Frew A, Hitz M(Eds.). Proceedings of the 9th International Conference for Information and Communication Technologies in Tourism, Innsbruck, Austria. Springer. Heidelberg, Berlin.

[52] Zipf A. 2003. Forschungsfragen zur benutzer-und kontextangepassten Kartengenerierung für mobile Systeme. Kartographische Nachrichten, 1/2003: 6-11. 